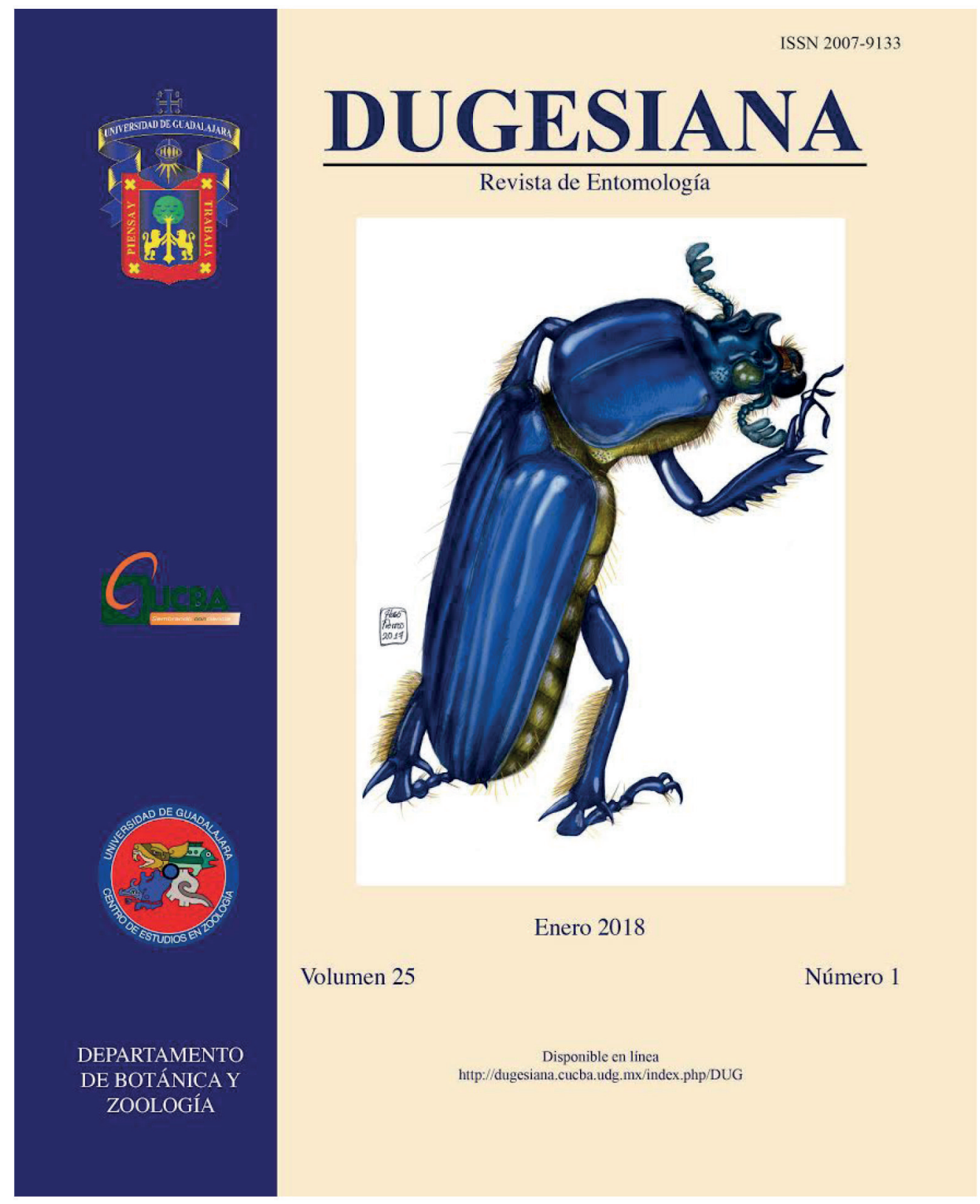

Dugesiana, Año 25, No. 1, enero 2018-junio 2018 (primer semestre de 2018), es una publicación Semestral, editada por la Universidad de Guadalajara, a través del Centro de Estudios en Zoología, por el Centro Universitario de Ciencias Biológicas y Agropecuarias. Camino Ramón Padilla Sánchez \# 2100, Nextipac, Zapopan, Jalisco, Tel. 37771150 ext. 33218, http://dugesiana.cucba.udg.mx/index.php/DUG, jose.navarrete@academicos.udg.mx. Editor responsable: José Luis Navarrete Heredia. Reserva de Derechos al Uso Exclusivo 04-2009-062310115100203, ISSN: 2007-9133, otorgados por el Instituto Nacional del Derecho de Autor. Responsable de la última actualización de este número: José Luis Navarrete Heredia, Editor y Ana Laura González-Hernández, Asistente Editorial. Fecha de la última modificación 1 de enero de 2018, con un tiraje de un ejemplar.

Las opiniones expresadas por los autores no necesariamente reflejan la postura del editor de la publicación.

Queda estrictamente prohibida la reproducción total o parcial de los contenidos e imágenes de la publicación sin previa autorización de la Universidad de Guadalajara. 


\title{
El caminar de un entomólogo: inicios, vicisitudes y logros
}

\section{The way of an entomologist: beginnings, vicissitudes and achievements}

\author{
Harry Brailovsky \\ Departamento de Zoología, Instituto de Biología, Universidad Nacional Autónoma de México, Apdo. Postal \# \\ 70153, 04510 Ciudad de México, México,E-mail: coreidae@ib.unam.mx
}

Para este homenaje el Dr. José Luis Navarrete-Heredia me pidió que diera una plática. La temática estaba abierta. En un principio maneje la opción de hablar sobre la sistemática del Orden Hemiptera-Heteroptera analizando cómo han ido variando los conceptos supra-genéricos; otra opción era el hablar de sus hábitos tróficos, y del tipo de ambiente en el cual se desplazan; otra era quizá hablar de cómo se recolectan, su importancia médica, su impacto en la agricultura, su importancia en el control biológico, sus formas estructurales fascinantes, sus grados de mimetismo tanto cromático como estructural, la o las funciones de sus secreciones glandulares (de ahí el nombre de chinches hediondas), los compuestos químicos que forman parte de ese fluido etc., pero finalmente pensé que cada uno de esos temas pueden ser consultados en la enorme literatura disponible a través de los métodos electrónicos actuales y es por ello que me plantee que sería más interesante hablarle a la gente joven que hoy nos acompaña de todo lo que un joven recién contratado debe escalar y seguir escalando para adentrarse en el mundo de la entomología y lo extrapolo a cualquier disciplina que el ser humano tome como oficio o profesión desde el arquitecto hasta el recadero; pero también estoy seguro de que los colegas aquí presentes ya establecidos en el campo de la entomología recordaran esos mismos pasos, más los escalones particulares que cada uno de nosotros hemos debido de tomar, porque no hay elevadores, olvídense de ellos, no hay elevadores, labrar el futuro corre por el esfuerzo de uno, por el apoyo de las autoridades institucionales (que desde aquí también aprovecho para agradecer a los Directores y Jefes de Zoología que han desfilado por las instalaciones del IBUNAM) y por las agencias que financian proyectos (CONACyT, CONABIO, DGAPA, etc).

El título propuesto "El Caminar de un Entomólogo: Inicios, Vicisitudes y Logros" es mi experiencia, la ofrezco a ustedes, con respeto, esperando poder impulsar a los jóvenes en el intrincado camino del científico, que escuchen el lado tortuoso, pero también los modestos éxitos y para ello, y como habrán notado, leeré el texto para calmar los nervios y que me entiendan porque de otra forma ni mi familia ni un traductor tendrían tiempo para saber de qué estoy hablando. Una pregunta que la gente suele hacer es ¿de cuantos géneros y especies consta el Orden Hemiptera-Heteroptera ?: la respuesta 5,819 géneros y 42,400 especies más lo que se acumule. ¿Cuantas han sido registradas para México? No tengo idea, me interesa más avanzar en el conocimiento de la misma que en recopilar lo ya conocido, pero sí puedo decir que falta mucho por hacer y esta respuesta la extrapolo a botánicos y zoólogos. Me preguntaran si estoy desarrollando una base de datos, diría que sí, pero también diría que lo más probable es que no me alcance el tiempo para completar la misma. De momento con el Biol. Ernesto Barrera se está preparando una base con la fotografía y la etiqueta con la localidad de cada especie de coreido presente en la colección del Instituto de Biología, incluyendo dentro de ella fotografías de los tipos.

La destrucción de la naturaleza, la contaminación del ambiente natural, el uso indiscriminado de biocidas, el asfaltado de las áreas verdes y otros muchos elementos colapsan las funciones de la biodiversidad, la cual es eliminada y donde aquellos profesionales tanto botánicos como zoólogos que son los únicos encargados de poder determinar las especies, dar el registro de los mismos, y entender el mundo taxonómico tan intrincado. Los taxónomos se ven y se han visto relegados por disciplinas que maravillosamente complementan la taxonomía pero que no la pueden sustituir como son los estudios de DNA, los análisis moleculares, etc., que repito coadyuvan de manera importante a entender el fino movimiento genérico y específico, pero que desgraciadamente no entienden que la base de dichos estudios son los taxónomos, los sistematas que deben pelear diariamente para que la gente de su propio gremio y aquí lo abro a ecólogos, etólogos, moleculares, genetistas, etc., también lo reconozcan dentro de la plataforma científica global.

La década y la nueva década para estudiar y proteger la biodiversidad dentro del planeta es una quimera. El cambio climático que es un hecho; la extinción de las especies que es un hecho; el aumento de genetistas (porque ahí está el trabajo), que es un hecho; y la falta de vocaciones para estudios taxonómicos que no es un hecho, me incitan a responder que esta afirmación es muy sencilla, cada institución tanto nacional como internacional está convencida de que contratar a un joven taxónomo a que cuente los pelos de una pata no es hacer ciencia en cambio contratar a un genetista que le pide esa pata a uno de los pocos taxónomos que aún quedan y que trabajan en otra dependencia dentro o fuera de su país eso si es hacer ciencia. Pero ese genetista probablemente no sabe cómo es el individuo con el cual está trabajando, es más ni 
siquiera tiene experiencia trabajado en el campo, ni lo ha recolectado y da por sentado que lo que hace es fuera de serie o sea es la moda actual.

En cambio si esa dependencia contratara a un taxónomo formado o en vías de formación con la opción de traer consigo estudios en genética se tendría el científico idóneo para esta nueva generación que compaginaría el conocimiento profundo de un campo dentro del mundo de los insectos y el conocimiento para adentrarse en estudios taxonómicos y genéticos y además a sus futuros alumnos podrá orientarlos en ambos aspectos del mundo científico actual.

La resiliencia es un concepto de moda que podemos definirla como la capacidad de un sistema para hacer frente al cambio. Es la capacidad del individuo para adaptarse con éxito a las tareas de la vida frente a la desventaja social, económica o a las condiciones adversas. La resiliencia en la cultura del taxónomo es evitar su extinción, es confrontar situaciones complicadas y seguir insistiendo ante los oídos sordos de la importancia de su especialidad. En otras palabras, resiliencia es la capacidad de levantarnos cuando la vida nos golpea, utilizando la habilidad fundamental a través del convencimiento y que las autoridades contratantes no se vean engañadas por reflectores de moda y si, en cambio, dinamicen los cuerpos y líneas de trabajo de su dependencia. La serenidad con que he vertido estos comentarios me satisface pero también me angustia, me atemoriza que la escalada fundamental para conjugar ambos campos sea una lucha de poder y no de entendimiento crítico.

\section{Breve historia}

Corría el año 1968, un año convulso en nuestro país con las olimpiadas presentes. La Universidad Nacional Autónoma de México cerró sus puertas durante un largo periodo y al reabrirlas y ajustar los tiempos decidí acercarme al Instituto de Biología para dar inicio a mi tesis de licenciatura. Para ello pedí autorización a la Dra. Leonila Vázquez García q. e. p. d., responsable de la Sección de Entomología (en aquella época no había curadores) para poder asistir a la sección correspondiente. Durante la entrevista le señalé mi interés en adentrarme en Coleoptera y como muchos jóvenes trabajar con cerambícidos. De inmediato me presentó al Dr. Santiago Zaragoza Caballero coleopterólogo que me brindo los primeros pasos prestándome el Arnett, que era un clásico de la época y el cual empecé a leer, sin embargo, el acceso a la colección general estaba muy restringida. Habían transcurrido cerca de 40 días cuando la Dra. Julieta Ramos homopteróloga y más tarde experta en insectos comestibles, me llamó a su escritorio y me dijo textualmente si quería conocer un insecto increíble; me acerque al microscopio y al verlo exclamé ¿qué es?, ella señaló: es una chinche de encaje, ¿y eso que es? respondí, es un tíngido ¿y eso qué es?, pertenece al Orden Hemiptera-Heteroptera; interrogué acerca de quién los trabajaba en México y la respuesta fue sencilla: nadie los estudia; de inmediato agradecí al Dr. Zaragoza por su tiempo y me acerque al Dr. Carlos Márquez Mayaudón investigador y especialista en ortópteros que después de escucharme accedió a dirigirme mi tesis la cual ocurriría en un transecto del Río Cuautla. Se desarrolló un plan de trabajo con recolectas mensuales de 4 días y a medida que esto ocurría empecé a conocer las técnicas de muestreo, el montaje y lo más complicado, como poner el nombre científico.

La colección de Heteróptera en aquella época contaba con cerca de 2,000 ejemplares la mayoría triatóminos (redúvidos) derivados de cultivos del Dr. Carlos Hoffman y del Dr. Federico Islas. La literatura era nula, sin embargo, contábamos con la Biología Centrali-Americana y por comparación traté de determinar las especies.

El Dr. Márquez me sugirió consultar el Biological Abstracts y el Entomological Abstracts, volúmenes depositados en la biblioteca de la institución. Después de algunos días aprendí el cómo y el qué buscar entresacando mis primeras tarjetas bibliográficas, así como las direcciones de los autores.

Envié una serie de cartas y más o menos un mes después, recibía respuesta del Dr. Herbert Ruckes adscrito al American Museum de la Ciudad de Nueva York, sin embargo, el remitente era el Smithsoniano de Washington a través del Dr. Richard C. Froeschner. Ese primer paquete de separatas me fue entregado por la Dra. Vázquez la cual me regañó por utilizar el título de Dr. Harry Brailovsky, cuando era solo un pasante de biología. El Dr. Márquez intervino y de manera amable le indicó que cuando uno envía un paquete pone Dr., o Dra., para así evitar conflictos con la persona a la cual va dirigida esa carta o paquete.

Por ello y desde siempre solo pongo el título de Doctor cuando se trata de un documento oficial. Abro un paréntesis para indicar que el título de Biólogo, Maestro en Ciencias, Doctor o Postdoc., es eso un simple título, lo que hagan después de obtenerlo, sus publicaciones, y contribuciones, son lo que hará brillar a ese individuo, no el restregar una hoja bonita de papel membretado.

Después de solucionar el problema y ante el éxito obtenido, agradecí al Dr. Froeschner su gentileza. ¿Qué paso con el Dr. Ruckes?, nada, él había fallecido varios años atrás, pero parte de sus separatas fueron depositadas en Washington para ser distribuidas entre los colegas que lo solicitaran. Por ello cada uno de Ustedes, siempre que soliciten algo y lo reciban deberán de inmediato agradecer la gestión del colega correspondiente. En Latinoamérica suele faltar esta gentileza final, y donde el que manda algo no sabe si llegó y cuando le vuelve a pedir esa misma persona, simplemente lo ignoran. Envié un cumulo de cartas a colegas de cada continente y a través de más de 48 años ininterrumpidos de carteo desde la máquina mecánica hasta los medios electrónicos, tenemos en el instituto más de 30,000 referencias hemipteriológicas y los libros más selectos del mismo. La biblioteca es y será siempre un referente. 
En 1970 obtuve el título de Biólogo, y en 1971 el de Maestro en Ciencias. Este proceso fue recompensado cuando el Dr. Márquez asume la jefatura de Zoología y me ofrece la beca para el doctorado el cual versó sobre la revisión del género Arvelius (Pentatomidae). En el inter se desarrollaron salidas a Valle de Bravo, a Guerrero y otros puntos para recolecta de material de ortópteros, hemípteros, etc.

A medida que la colección de Hemíptera crecía y que hoy en día cuenta con cerca de 625,000 ejemplares debidamente montados y etiquetados surgió la inquietud de conocer el campo y recibir capacitación dentro del mismo. Me acerqué al Dr. Márquez y le planteé la necesidad de visitar colecciones internacionales. Mi plan de vistas fue aprobado y entre julio y agosto de 1974 asistí a la Universidad de Connecticut, en Storrs (Dr. James A. Slater), al American Museum de Nueva York (Dr. Pedro Wygodsinsky) y al Museo Nacional de Historia Natural de Washington, Smithsoniano (Dr. Richard C. Froeschner). El aprendizaje fue intensivo tanto en reconocimiento estructural que incluía la manipulación de la genitalia de ambos sexos, técnicas finas para estudios de glándulas senescentes, técnicas de colecta directamente en campo y utilizando equipos propios para Heteroptera, etc. La supervisión fue intensa y al final de la misma cada institución me donó una colección sinóptica del grupo que ascendió a un total 17 cajas entomológicas que marcó el inicio de esta colección.

Para este primer viaje llevé el material de Lygaeoidea para que a través del Dr. Slater pudiera obtener las determinaciones de la familia que me empezaba a interesar y pensando al futuro cercano. Dicho personaje determinó el material a nivel de especie en unas pocas horas. Recuerdo que le pregunte, Dr. Slater ¿cómo hace Ud., para trabajar la hemipterofauna Africana, Australiana y además la neotropical ¿y su respuesta fue muy clara "TRABAJANDO". Viendo a través de la ventana de su oficina que daba al jardín, me dije para mis adentros que haría lo mismo y por ello en Lygaeoidea y Coreoidea trabajo la fauna mundial. Para ello y a través de tantos años, he recurrido a los museos internacionales visitando un buen número de ellos, fotografiando los tipos, recibiendo en calidad de préstamo un amplio número de ejemplares, comprando o intercambiando material, aplicando proyectos de recolecta intensa a través de la República Mexicana, contratando jóvenes estudiantes y recolectores, dirigiendo servicios sociales etc., y con ello la colección ha mantenido un crecimiento continuo.

Las colecciones mexicanas dispersas en cada uno de los Estados de la Republica, y salvo excepciones, son deficientes y los jóvenes o no tan jóvenes investigadores o profesores están más ocupados en dictar clases, sumergirse en papeleo administrativo, pelear por alfileres, o cajas o anaqueles con nula respuesta de las autoridades que podrían realmente auxiliar a conocer que hay en cada uno de sus Estados o cuando menos en los Parques Nacionales y Reservas repartidas a través del mismo. Reitero como lo he dicho a través de otras pláticas que las Colecciones Regionales son básicas si realmente queremos adentrarnos en la biodiversidad estatal.

Finalmente, en 1976 obtuve el Doctorado, el Dr. Márquez llegaba a la Dirección del Instituto de Biología y me extendía el contrato de Investigador tiempo completo. Después de firmarlo me dijo, te doy la plaza, el resto depende de ti, respondí, no lo defraudaré.

Estas simples frases deben quedar en la mente de los aquí presentes. Obtener un nombramiento de profesorinvestigador (que es la tendencia actual) que por tanto tiempo fue añorado (hoy en día después de uno o más postdocs) no es para sentirse satisfechos; lo que sigue es volcarse en su investigación cualquiera que sea su especialidad, dar lo mejor de sí, no rendirse ante las muchas barreras que la sociedad y porque no la propia dependencia quiere remarcar y seguir adelante. Transmitir su conocimiento a posibles alumnos y dejar a estos que tomen riesgos para también crecer.

En 1977 regresé a las mismas tres dependencias americanas antes señaladas pero ahora con 31 años de edad y con ciertos signos de madurez para volcarme en el estudio de Lygaeoiddea. Los numerosos trabajos desarrollados se colapsaron cuando en 1985 di por concluida mi contribución en Lygaeidae para evitar la confrontación entre discípulos del Dr. Slater (el lygaeidologo más reconocido del mundo y autor del catálogo del mismo) y mi persona.

Ese año de 1985 y en compañía del Biol. Ernesto Barrera Vargas y del M. en C. Enrique Mariño Pedraza, nos refugiamos en la estación de Biología Tropical de los Tuxtlas, en Veracruz, para analizar mi siguiente destino dentro del campo de la Hemipteriología. Llevamos literatura abundante y durante 8 días examiné cada familia de Heteroptera, quien la trabajaba, que especialistas trabajaban con ella, que museos albergaban los tipos, de que literatura gozaba, que colección sinóptica tenía, en qué idioma usualmente estaban escritos, etc., lentamente se tamizó el campo concluyendo que trabajaría en Coreoidea y a la fecha estoy satisfecho con la difícil decisión de cambiar de especialidad y por ello señalo: "mi corazón está con Lygaeoidea pero mi mente con Coreoidea".

El avance en este nuevo campo fue muy rápido, la experiencia, la literatura siempre al día, el material montado, los servicios sociales, los tesistas, los contactos, los proyectos, los colaboradores nacionales e internacionales, la entrega al trabajo, el apoyo institucional y años después los sistemas computacionales promovieron este nuevo paso.

Publicar es sencillo lo difícil es teclear y descargar la información obtenida a través de la microscopia; adaptar los textos a la revista seleccionada es laborioso; generar libros o monografías es dantesco por lo cual no piensen en ello, al principio de sus carreras hagan descripciones sencillas, más tarde revisión de un género, más adelante claves y paso a paso llegarán a un compendio de información; nunca se estanquen en un trabajo glorioso, nunca lo harán 
y si se sumergen no saldrán bien librados de ese hoyo; sean sencillos en sus proyectos, no busquen complicarse las ideas; sigan al autor o a los autores más importantes del campo por ustedes, seleccionados; colecten y procesen todo lo que capturen; y nunca se den por satisfechos con lo que hicieron en ese año, en otras palabras no detengan la maquinaria por ser casi fin de año. Los proyectos a corto y mediano plazo permitirán el de largo plazo; en cambio proyectos a largo plazo sin sustento los harán distraerse de sus inquietudes académicas; la frustración económica y académica es transitoria, encontrarán dificultades al principio de sus carreras, pero después serán más complicadas y sólo aquel que persevera podrá ver luz al final del túnel y no porque ya éste muerto, no, por el contrario es la esperanza, es la renovación de su propio proyecto que finalmente estará despejándose.

Además quisiera alertarlos acerca del síndrome de la página en blanco. Cada uno de nosotros, independientemente de la edad, tenemos momentos donde no sabemos cómo iniciar un trabajo, como fortalecer un artículo ya iniciado o en el peor de los casos como organizar mis notas dispersas en mi escritorio o en mi unidad de cómputo.

Esa página en blanco o en Word no se mueve, la crisis se incrementa cuando tenemos el compromiso de mandar ese artículo o bien uno mismo se presiona por querer forzar la gestación de un nuevo trabajo.

¿Qué debe hacerse ante ese problema?:

- Cerrar la oficina, apagar el equipo de cómputo y llevarse artículos de la especialidad y publicados por líderes del campo. Refugiarse en la biblioteca, en la casa o en algún sitio y leerlos, releerlos y buscar la inspiración que puede llegar en un día, o en una semana o aún más tarde.

- Conjuntar las notas dispersas y reunirlas en un todo y el resto destruirlas para que no hagan ruido.

- Salir al campo, o platicar con los colegas y buscar el encontrarse con uno mismo.

Recibido: 25 de octubre 2017

Aceptado: 23 de noviembre 2017
- Regresar a la oficina, y pasar a la colección general de la institución donde está depositada la colección de su especialidad. Verla, entresacar otros grupos, analizarlos bajo el microscopio, perder el tiempo y al unísono calmar la inquietud interna.

- Eso es lo que yo hago y créanlo, "nunca resulta", pero algo se conecta y la página cobra vida y uno se reencuentra, congratulándose de que todavía está tratando de madurar como individuo y como científico.

Espero que estos mensajes, salpicados de consejos o puntos vivenciales sean recordados y que puedan ser aplicados en su vida tanto académica como familiar.

Finalizó esta platica agradeciendo a mi esposa Jacqueline Signoret Poillon q.e.p.d., a mis hijas Kalincka, Claudine y Francoise, a mis nietos Alan, Kevin, Pablo y Nicole y a Bella Caltum Rayek el reconocer que muchas veces me es y me sigue siendo más importante ver una chinche que ver el espléndido paisaje donde cada uno de ellos y de ellas están parados y pese a ello me han entendido y me han cobijado a través de muchas décadas.

Muchas Gracias.

México, Ciudad de México, 18 de Octubre 2017.

\section{AGRADECIMIENTOS}

Agradezco al Dr. José Luis Navarrete-Heredia por haber gestionado e impulsado este sentido reconocimiento el cual comparto con el Dr. Carlos Márquez Mayaudon que me brindó la oportunidad de trabajar en el Instituto de Biología de la UNAM; al Biólogo Ernesto Barrera Vargas compañero de tantos y tantos años; a las M. en C. Cristina Mayorga Martínez y Guillermina Ortega León que siempre me han apoyado en las funciones de gabinete incluyendo el espléndido montaje del material recolectado; y de manera póstuma al Dr. Luis Cervantes Peredo alumno y más tarde colega que por circunstancias no entendibles se nos adelantó en el viaje. 